\title{
Neonatal supraventricular tachycardia and necrotizing enterocolitis: case report and literature review
}

\author{
Federico Mecarini ${ }^{*} \mathbb{D}$, Federica Comitini, Flaminia Bardanzellu, Paola Neroni and Vassilios Fanos
}

\begin{abstract}
Background: Necrotizing enterocolitis (NEC) and supraventricular tachycardia (SVT) are serious emergencies in the neonatal period. Although these conditions are recognized as distinct pathologies, literature reports suggest that recurrent episodes of SVT may predispose patients to NEC via disturbances in mesenteric blood flow and a decrease in tissue perfusion.

Case presentation: We present a case of a preterm infant affected by recurrent episodes of SVT who developed the initial stage of NEC on the 17th day of life. Moreover, a detailed description of all the cases described in the literature is reported.

Materials and methods: An integrative review of the updated literature in the Medline database and PubMed and scientific books and articles was conducted. The research from October 2019 to December 2019 was searched for with $\mathrm{MeSH}$ and free terms (necrotizing enterocolitis, supraventricular tachycardia) and was linked by Boolean operators.

Conclusions: SVT can be considered a risk factor for the development of NEC. Therefore, clinicians should have a high level of suspicion for NEC in infants affected by SVT. This article is the first structured literature review analysing the association between SVT and NEC.
\end{abstract}

Keywords: Necrotizing enterocolitis, Supraventricular tachycardia, Neonatal intensive care

\section{Introduction}

Necrotizing enterocolitis (NEC) is the most common gastrointestinal emergency that mainly affects premature infants in neonatal intensive care units (NICUs). NEC is considered a multifactorial disease, and its pathogenesis is not yet completely understood. Supraventricular tachycardia (SVT) is the most common pathological tachycardia in newborns, with an estimated prevalence of up to 1 in 1000 children. SVT is a heterogeneous collection of dysrhythmias characterized as a narrow-complex tachycardia originating above the level of the AV junction [1]. SVT could originate through a mechanism of retrograde conduction

\footnotetext{
* Correspondence: federicomecarini@gmail.com

Neonatal Intensive Care Unit, Department of Surgical Sciences, University of Cagliari, Cagliari, Italy
}

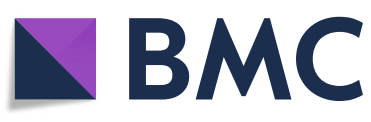

(c) The Author(s). 2020 Open Access This article is licensed under a Creative Commons Attribution 4.0 International License, which permits use, sharing, adaptation, distribution and reproduction in any medium or format, as long as you give appropriate credit to the original author(s) and the source, provide a link to the Creative Commons licence, and indicate if changes were made. The images or other third party material in this article are included in the article's Creative Commons licence, unless indicated otherwise in a credit line to the material. If material is not included in the article's Creative Commons licence and your intended use is not permitted by statutory regulation or exceeds the permitted use, you will need to obtain permission directly from the copyright holder. To view a copy of this licence, visit http://creativecommons.org/licenses/by/4.0/ The Creative Commons Public Domain Dedication waiver (http://creativecommons.org/publicdomain/zero/1.0/) applies to the data made available in this article, unless otherwise stated in a credit line to the data. (automatic tachycardia). In the neonatal period, SVT may be asymptomatic if the episodes are brief or may present with signs of heart failure, such as poor feeding, sweating and shortness of breath, due to a prolonged episode [2]. In haemodynamically stable patients, vagal manoeuvres, such as the "diving reflex", are the first-line nonpharmacologic therapies. If they prove ineffective, adenosine is administered. Maintenance therapy with antiarrhythmic drugs is carried out in cases of recurrent episodes, while spontaneous resolution usually occurs in the first year of life in most cases [3].

Recent data in the literature suggest a possible association between SVT and NEC. However, little is currently known about this association regarding the pathogenic 
mechanisms, factors that affect susceptibility, correct management and prognosis.

\section{Case report}

We report a case of a $29^{+6}$ week preterm infant from a twin pregnancy and delivered by caesarean section. The Apgar score was 7 at $1 \mathrm{~min}$ and 8 at $5 \mathrm{~min}$. The birth weight was $1380 \mathrm{~g}$, which was appropriate for gestational age (AGA). The pregnancy was marked by twin-to-twin transfusion treated by laser therapy in utero and complicated by the death of one twin before birth. At birth, the infant was admitted to the NICU due to prematurity and respiratory distress and received ventilation support for 21 days. Parental nutrition and trophic feeding $(3 \mathrm{ml} / \mathrm{kg} /$ day) were immediately started with maternal milk. The feeds gradually advanced at a rate of $10-20 \mathrm{ml} / \mathrm{kg} /$ day according to the standardized feeding regime of our NICU while monitoring for early signs of feeding intolerance. On the 13th day of life, full enteral feeding was reached $(150 \mathrm{ml} / \mathrm{kg} /$ day $)$, and parental nutrition was discontinued. Human milk fortifier (Aptamil BMF) was started at a concentration of $2.2 \%$ when the milk volume reached $100 \mathrm{ml} / \mathrm{kg} /$ day of human milk.

On the 16th day of life, the patient had recurrent episodes of SVT of 300-390 beats per minute (bpm) that were initially self-limiting or responded to vagal manoeuvres. Echocardiogram revealed a structurally normal heart with good contractility. Pharmacologic therapy with flecainide was administered orally at a dose of 4 $\mathrm{mg} / \mathrm{kg} /$ day twice daily due to recurrent episodes of SVT. The infant remained haemodynamically stable with good perfusion and oxygen saturation throughout the episodes of SVT. Non-invasive blood pressure monitoring was normal, and the oxygen saturation values remained above $95 \%$ with non-invasive ventilation (high-flow nasal cannula therapy without oxygen delivery). Blood gas analysis performed after episodes of SVT did not report acid-base disorders, with a maximum lactate value of $2.1 \mathrm{mmol} / \mathrm{L}$. Procalcitonin (PCT), C-reactive protein (CRP), blood count and urine samples were in the normal ranges. Moreover, the abdominal ultrasound assessment confirmed no evidence of hepatomegaly.

On the 17th day of life, bloody stools and abdominal distension were observed. Abdominal X-ray and ultrasound imaging were performed, showing no evidence of intestinal pneumatosis, portal venous gas or other radiographic features of NEC. The CRP levels began to increase, reaching levels of $17.8 \mathrm{mg} / \mathrm{l}$ on day 18 , while PCT always remained negative. Taking into account the presence of potential NEC, enteral nutrition was discontinued, and double antibiotics (ampicillin and gentamicin) and parenteral nutrition were started. Antiarrhythmic therapy was switched to amiodarone with a maintenance dose of 5 micrograms $/ \mathrm{kg} /$ minute, since oral flecainide was not possible. A conservative approach with bowel rest, parenteral feeding and antibiotics controlled NEC from progressing to an advanced stage, and surgical treatment was not necessary. Enteral feeding was progressively reintroduced 7 days after the onset of the initial stage of NEC without disease recurrence. He was discharged after 59 days in good clinical condition and continued antiarrhythmic therapy with $5 \mathrm{mg} / \mathrm{kg} /$ day of fleicainide administered orally in three doses.

\section{Discussion}

A case of a preterm infant with recurrent episodes of SVT who developed the initial stage of NEC on the 17 th day of life was presented. NEC is the most common gastrointestinal emergency in the NICU [4]. Although this fatal disease predominantly affects preterm infants, especially those with a very low birthweight $(<1500 \mathrm{~g})$ [5], $13 \%$ of reported cases occur in full-term infants [6-8]. In these neonates, NEC mostly occurs in association with congenital heart disease (CHD) [4] that might lead to poor mesenteric artery perfusion [9-11]. NEC is often staged according to Bell's 1978 system. Staging by Bell's criteria has been recently supported by a statistical pattern analysis of clinical and radiological variables [12]. SVT is one of the most frequent tachyarrhythmia requiring emergency care in neonates [13]. SVT is usually asymptomatic and well tolerated in infants, but some patients may present signs of heart failure due to a prolonged episode. Although SVT management includes cardioversion using vagal manoeuvres, the primary therapy for neonates involves pharmacological agents. Our case is a preterm neonate with no structural congenital heart disease. The abdominal signs of NEC (bloody stools and abdominal distension) started after 17 days of life after full enteral feeding was achieved with maternal milk. The main identifiable risk factors for NEC in our patient were episodes of SVT, prematurity and low birth weight.

The association between NEC and SVT in newborns has been previously described in seven case reports in the literature Table 1) starting in 1998 [6, 14-17]. Two cases were of full-term infants, and four were of preterm infants. In all cases, SVT preceded the clinical onset of NEC. The first case was of a full-term infant with multiple congenital abnormalities reported by Hajivassiliou et al. in [16]. In the same year, Khalak et al. reported the first case of a preterm infant treated pre- and postnatally for SVT who developed fatal NEC $28 \mathrm{~h}$ after starting enteral feeding [17]. Fifteen years later, Hanna et al. reported a case of a preterm infant with recurrent episodes of SVT followed by NEC on the 11th day of life who underwent surgical resection of the compromised bowel tract [15]. Two cases of late preterm infants, one with 


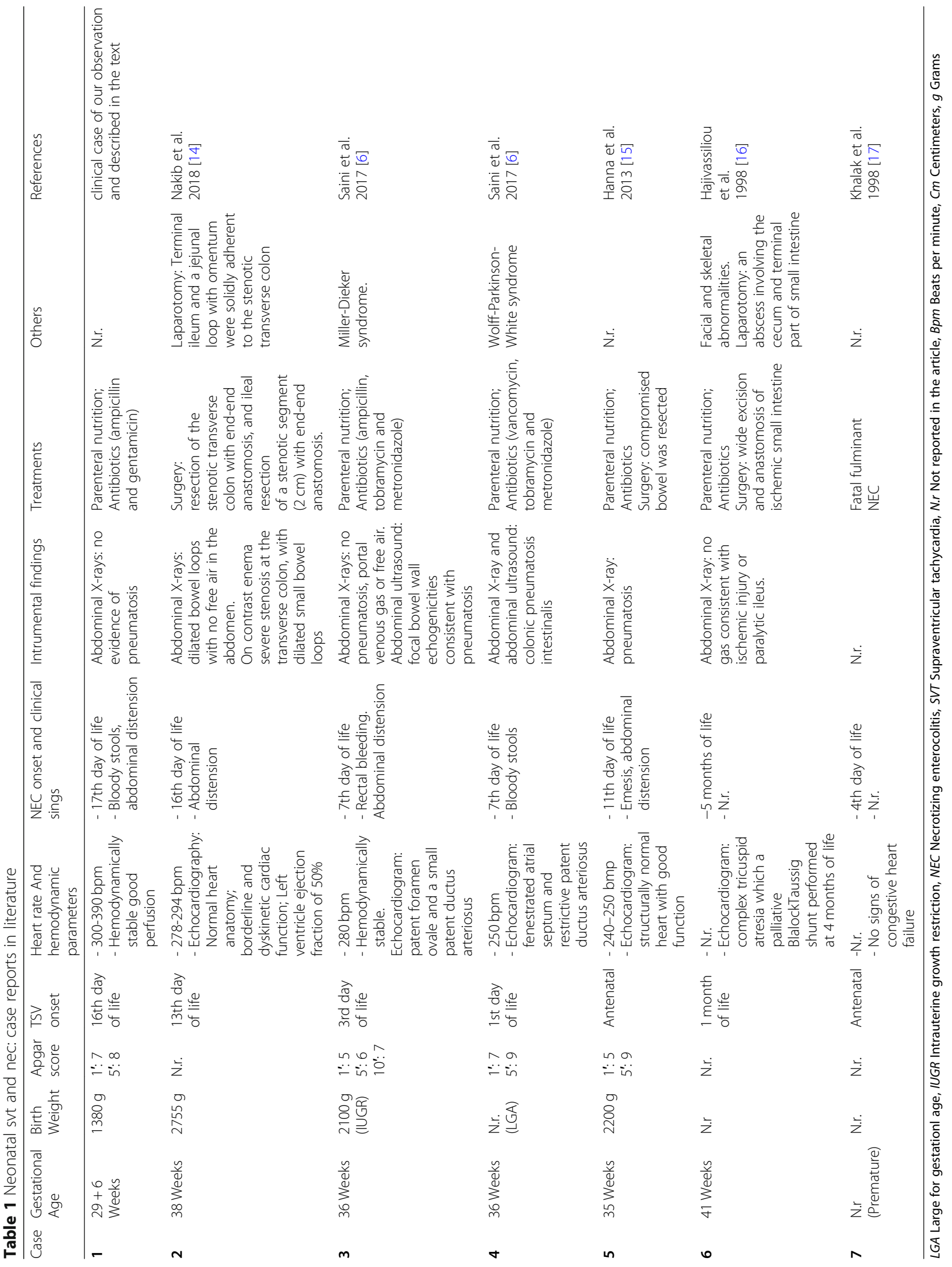


intrauterine growth restriction (IUGR) and one large for gestational age (LGA), affected by NEC after recurrent episodes of SVT were presented by Saini et al. in 2017 [6]. The most recent case report describes a full-term infant who was breastfed and developed NEC 3 days after SVT onset [14]. The seventh case was a 15-month-old boy who presented with shock and SVT following a 12-h history of worsening abdominal pain and vomiting reported by Jacombs et al. [18]. The review focused on cases showing clinical onset in the first year of life and therefore excluded the aforementioned case.

Several theories have been formulated in an attempt to explain the origin of the correlation between SVT and NEC. The intestinal blood supply is provided by the celiac and superior and inferior mesenteric arteries, and it is widely known that ischaemia is an important contributing factor to the development of NEC [19]. A mechanism of intestinal hypoperfusion associated with $\mathrm{NEC}$ is the diving reflex, constituted by the redistribution of cardiac output to ensure brain and heart perfusion [20]. Recent literature reports suggest that recurrent episodes of SVT may predispose patients to NEC via disturbances in mesenteric blood flow [6, 14-17]. During the haemodynamic instability caused by SVT, there is an increase in vascular resistance that reduces blood flow to the mesentery, known as the "steal phenomenon". Decreased tissue perfusion caused by diastolic backflow to areas of lower resistance [4] leads to hypoperfusion and subsequent hypoxic-ischaemic injury of the mucosa. Ischaemia induces the activation of the proinflammatory cascade and mediators such as TNF-alpha, leukotrienes, prostaglandins, complement mediators, and fragments. Furthermore, norepinephrine release and vasoconstriction seem to determine splanchnic ischaemia. The stabilization of cardiac output with control of SVT may cause oxygen free radical production with reperfusion injury. Persistent tachycardias can lead to haemodynamic compromise, but some authors suggest that NEC can also occur in infants affected by SVT without evidence of a significant haemodynamic compromise [14].

In conclusion, the exact aetiology and pathogenesis of NEC remain incompletely understood, and NEC is generally considered a multifactorial disease. Preterm birth, low birth weight, enteral feeding, infections, gastrointestinal tract immaturity and intestinal hypoxia-ischaemia are considered potential risk factors [21]. The intestinal microbiome and altered innate and adaptive host immune responses seem to play key roles. Furthermore, some authors suggest that alterations in the gut-brain axis with vagal dysregulation may also be involved in NEC pathogenesis [22].

Our case and recent reports in the literature suggest that a high level of awareness of NEC development should be maintained in the presence of SVT. Intestinal ischaemia due to SVT could have a role in causing NEC, and SVT could be a risk factor for the development of NEC. Whether SVT is simply associated with NEC or has a causative role in the pathogenesis of NEC is still under debate. Further studies are required to better identify the pathological mechanism underlying these two pathologies.

\section{Abbreviations}

NEC: Necrotizing enterocolitis; NICUs: Neonatal intensive care units;

SVT: Supraventricular tachycardia; AGA: Appropriate for gestational age; PCT: Procalcitonin; CRP: C-reactive protein; CHD: Congenital heart disease; IUGR: Intrauterine growth restriction; LGA: Large for gestational age

\section{Acknowledgements}

None declared.

\section{Authors' contributions}

F.M. and V.F. conceived of the study and contributed to the design of the research, to the analysis of the results and to the writing of the manuscript. P.N., F.B. and F.C. helped draft the manuscript. All authors read and approved the final manuscript.

\section{Funding}

The authors certify that they have no affiliations with or involvement in any organization or entity with any financial interest or non-financial interest in the subject matter or materials discussed in this manuscript.

\section{Availability of data and materials}

Data sharing not applicable to this article.

Ethics approval and consent to participate

Not applicable.

Consent for publication

Not applicable.

\section{Competing interests}

The authors declare that there are no conflicts of interest regarding the publication of this paper.

Received: 3 January 2020 Accepted: 28 July 2020

Published online: 26 August 2020

\section{References}

1. Spearman AD, Williams P. Supraventricular tachycardia in infancy and childhood. Pediatr Ann. 2014;43(11):456-60.

2. Richardson C, Silver ES. Management of Supraventricular Tachycardia in infants. Paediatr Drugs. 2017;19(6):539-51.

3. Neroni P, Ottonello G, Manus D, Atzei A, Trudu E, Floris S, Fanos V. Paroxysmal supraventricular tachycardia: physiopathology and management. JPNIM. 2014;3(2):e030243.

4. Bubberman JM, van Zoonen A, Bruggink JLM, van der Heide M, RMF B, Bos $A F$, et al. Necrotizing Enterocolitis associated with congenital heart disease: a different entity? J Pediatr Surg. 2019;54(9):1755-60.

5. Stoll BJ, Hansen N, Bell EF, Shankaran S, Laptook AR, Walsh MC, et al. Neonatal outcomes of extremely preterm infants from the NICHD Neonatal Research Network. Pediatrics. 2010;126(3):443-56.

6. Saini J, Moore A, Hodgson K. Necrotising enterocolitis after supraventricular tachycardia: an unusual precursor to a common problem. BMJ Case Rep. 2017;2017:bcr-2017-219675.

7. Wiswell TE, Robertson CF, Jones TA, Tuttle DJ. Necrotizing enterocolitis in full-term infants. A case-control study. Am J Dis Child. 1988;142(5):532-5.

8. Short SS, Papillon S, Berel D, Ford HR, Frykman PK, Kawaguchi A. Late onset of necrotizing enterocolitis in the full-term infant is associated with increased mortality: results from a two-center analysis. J Pediatr Surg. 2014; 49(6):950-3 
9. Lambert DK, Christensen RD, Henry E, Besner GE, Baer VL, Wiedmeier SE, et al. Necrotizing Enterocolitis in term neonates:data from a multihospital health-care system. J Perinatol. 2007;27(7):437-43.

10. Al Tawil K, Sumaily H, Ahmed IA, Sallam A, Al Zaben A, Al Namshan M, Crankson S. Risk factors, characteristics and outcomes of necrotizing enterocolitis in late preterm and term infants. J Neonatal-Perinatal Med. 2013;6(2):125-30

11. Christensen RD, Lambert DK, Baer VL, Gordon PV. Necrotizing enterocolitis in term infants. Clin Perinatol. 2013;40(1):69-78.

12. Juhl SM, Hansen ML, Gormsen M, Skov T, Greisen G. Staging of necrotising enterocolitis by Bell's criteria is supported by a statistical pattern analysis of clinical and radiological variables. Acta Paediatr. 2019;108(5):842-8.

13. Srinivasan C, Balaji S. Neonatal supraventricular tachycardia. Indian Pacing Electrophysiol J. 2019;50972-6292(19):30115-9.

14. Nakib G, Sajwani S, Abusalah Z, Abdallah A, Ibrahim N, Fattah A, et al. Recurrent supraventricular tachycardia and necrotizing enterocolitis: a causative role or a simple association? A case report and literature review. Pediatr Rep. 2018;10(3):7636.

15. Hanna MH. Necrotizing enterocolitis after recurrent supraventricular tachycardia. J Neonatal-Perinatal Med. 2013;6(4):359-61.

16. Hajivassiliou CA, Pitkin J. Recurrent necrotizing enterocolitis associated with episodes of supraventricular tachycardia. J Pediatr Surg. 1998:33(10):1569-70.

17. Khalak R, Chess PR. Fulminant necrotizing enterocolitis in a premature neonate treated for supraventricular tachycardia. J Perinatol. 1998;18:306-7.

18. Jacombs AS, Cross KM, Holland AJ, Wilkins BH. Supraventricular tachycardia as a presenting feature of volvulus in a 15-month-old boy. J Paediatr Child Health. 2009;45:389-90.

19. Chen Y, Chang KT, Lian DW, Lu H, Roy S, Laksmi NK, et al. The role of ischemia in necrotizing enterocolitis. J Pediatr Surg. 2016;51(8):1255-61.

20. Watkins DJ, Besner GE. The role of the intestinal microcirculation in necrotizing enterocolitis. Semin Pediatr Surg. 2013;22(2):83-7.

21. Lin PW, Stoll BJ. Necrotising enterocolitis. Lancet. 2006;368(9543):1271-83.

22. Bellodas Sanchez J, Kadrofske M. Necrotizing enterocolitis. Neurogastroenterol Motil. 2019;31:e13569.

\section{Publisher's Note}

Springer Nature remains neutral with regard to jurisdictional claims in published maps and institutional affiliations.

Ready to submit your research? Choose BMC and benefit from:

- fast, convenient online submission

- thorough peer review by experienced researchers in your field

- rapid publication on acceptance

- support for research data, including large and complex data types

- gold Open Access which fosters wider collaboration and increased citations

- maximum visibility for your research: over $100 \mathrm{M}$ website views per year

At $\mathrm{BMC}$, research is always in progress.

Learn more biomedcentral.com/submissions 